\title{
The Role Of Organizational Justice And Ethical Frameworks On Attitudes Toward Affirmative Action: The Moderating Role Of Organizational Support
}

Edward I. Fubara, Campbell University, USA Amy McMillan-Capehart, East Carolina University, USA Orlando C. Richard, University of Texas at Dallas, USA

\begin{abstract}
The current study explores some of the challenges associated with Affirmative Action (AA) by clarifying the relationship between individuals' ethical frameworks and equality justice norms and their effects on attitudes toward AA specifically targeting African Americans. The study reveals that employer support for affirmative action plans and programs not only reduce negative attitudes toward AA but also moderate the effects of ethical frameworks and equality values on such attitudes. More specifically, consequentialist ethical values relate negatively and nonconsequentialist ethical values relate positively to attitudes toward affirmative action. Additionally, organizational support positively moderates the relationship between both equality norms and consequentialist ethical values and attitudes toward affirmative action for African Americans. Implications for future research and practice are offered.
\end{abstract}

Keywords: Affirmative Action, Ethical Frameworks, Organizational Justice, Consequentialism

\section{INTRODUCTION}

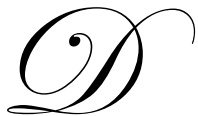

iversity initiatives are among the most contentious, controversial and challenging managerial activities in the contemporary American workplace (Chang, 1996; Opotow, 1996). Affirmative action (AA) programs are undoubtedly the most contentious (Crosby, et al., 2006; Kravitz \& Klineberg, 2000).

In spite of the laudable goals of AA, the concept and the various programs that stem from it have been met with considerable opposition, even from those whom they are designed to help (i.e. women and members of ethnic minority groups). Affirmative action initiatives are often seen as unfair, unjust, or unethical. Extant research provides a number of attributions for these negative reactions, many of which are rooted in deep-seated individual values, including modern racism, belief in the dominant ideology of opportunity, and simple self-interest (Kluegel \& Smith, 1983); political ideology (Fried et al., 2001); fairness judgments (Nacoste, 1990); and ethics (Blackstone \& Heslep, 1977). Note that a comprehensive review of the literature on attitudes toward affirmative action is beyond the scope of this study. Although previous researchers have chronicled various predictors of attitudes toward affirmative action (see for example Crosby et al., 2006 for a review), our study is unique in attempting to manipulate factors that affect these attitudes.

It is important to point out that while many organizations are forced to implement affirmative action programs (AAPs), voluntary programs concerned with including both merit and demographic group identity in 
decision making are also put into practice (Konrad \& Linnehan, 1995). These identity conscious initiatives take into account an individual's gender, race, national origin, or other protected identity. As with AAPs, the goal of these programs is to remedy discrimination, redress past injustices, and achieve a fair and visible representation in leadership positions (Konrad \& Linnehan, 1995). While diversity conscious initiatives result in negative attitudes and consequences, it should be noted that we are concerned primarily with AAPs. We focus specifically on affirmative action targeting African Americans since research indicates that such programs often trigger more negative responses than generically described affirmative action efforts (Bobo \& Kluegel, 1993).

Despite pervasive resistance to these programs and the changes in the contemporary legal landscape, both passive and active efforts to promote equal employment opportunity remain a part of today's organizational reality in one form or another. In addition, the history of the American workplace, and the lingering presence of workplace discrimination suggest that AAPs have not outlived their usefulness (Bertrand \& Mullainathan, 2004; Johnston \& Packer, 1987; Kravitz, 1995; Kravitz \& Platania, 1993). AA and related identity conscious practices also have potential application in a number of countries outside of the United States such as Canada and England where multiculturalism and racial reconciliation are important issues. These programs also carry potential benefits for emerging multiethnic nations such as Iraq and South Africa. Indeed the wide-ranging relevance and potential impact of these efforts indicates that their study is an important problem both for scholars and practicing managers -- a problem that merits considerable and careful investigation.

Note that this paper does not attempt to make a normative statement about the appropriateness or effectiveness of affirmative action. It is written from a practical, not a political perspective. Although there are a number of efforts to eliminate affirmative action from American society we expect that some form of these employment practices will continue to exist in the United States for several years to come. Our paper remains relevant and valuable as a tool for assisting in improving attitudes and subsequent behaviors within organizations.

Given that these programs are expected to exist for some time to come, it is logical for the research agenda to include the investigation of ways to make them more palatable both to those affected by them and to observers. In addition, given that affirmative action is only part of a larger continuum of identity conscious initiatives (Kravitz, 1995) we expect that reactions to affirmative action may generalize to other identity-conscious organizational efforts, such as diversity training, minority mentoring programs and the establishment of organizational diversity offices/departments.

Again, assuming that affirmative action and other similar efforts will continue to exist in the American workplace, research is necessary to uncover methods of changing negative attitudes toward them. The current study clarifies the relationship between individuals' ethical frameworks and their attitudes toward AA. In addition, the study endeavors to find a way to reduce negative attitudes toward AA such as on employer support of affirmative action plans and programs. For example, Clayton and Crosby (1992) suggest that in order to be successful, support for AA must come from the top of the organization. Hitt and Keats, (1984) found that commitment from top management was perceived to be the most important predictor of AA success. Thus, this study investigates the roles of both individual and organizational factors impacting attitudes toward affirmative action with the intent of identifying mechanisms that generate more positive perceptions.

\section{AFFIRMATIVE ACTION, JUSTICE, ETHICAL FRAMEWORKS, AND EMPLOYER SUPPORT}

Kravitz (1995) and later Kravitz and Klineberg (2000) offer a conceptual model to explain how AA attitudes are formed. The model includes predictors of AA attitudes based on theoretical support and previous research. These predictors are categorized by relevant beliefs and individual characteristics. In particular, relevant beliefs include attitudes regarding the judged fairness of AAPs, and the extent of discrimination experienced by different demographic groups. Individual characteristics included beneficiary status, personal variables, and other demographic characteristics. Beneficiary status refers to whether or not an individual or group will benefit from AA. This status includes ethnicity and gender. Personal variables tested in Kravitz and Klineberg's (2000) model included political orientation and experiences with discrimination. Finally, the other demographic characteristics included variables such as age, education, and income; and belief in the dominant ideology - a notion that everyone 
has the opportunity to succeed and that thus, failure is a result of individual shortcomings (Kluegel and Smith, 1986). The model is not intended to be comprehensive; consequently the authors recommended that future research develop a richer taxonomy of variables that explain attitudes toward AA. We extend Kravitz and Klineberg's model to include individuals' justice and ethical frameworks as explanations of AA attitudes. In addition, the current study suggests that organizational support for AAPs can have a positive impact on individual attitudes.

\section{Organizational Justice}

The first analytical perspective examined in this study is drawn from the organizational justice literature. Perceptions of fairness have been found to be one of the strongest predictors of AA attitudes (Cropanzano et al., 2005; Kravitz, 1995; Taylor-Carter et al., 1995). Individuals' justice frameworks determine what is perceived as fair or unfair. We examine the impact of these justice frameworks on individuals' attitudes toward affirmative action. While Kravitz and Klineberg's (2000) model of AA attitudes included perceptions of fairness, we believe that a more detailed examination is necessary. In particular, they tested perceptions of fairness with responses to one statement "Affirmative Action policies give unfair advantages to minorities and women." Answers were indicated with either $1=$ disagree or $2=$ agree. Their results suggest that perceptions of fairness are indeed a significant factor contributing to AA attitudes. However, a more comprehensive explanation is necessary. As such, we extend their model by examining equality norms of organizational justice and their impact on attitudes toward AA.

Our second approach to addressing individuals' responses to AA is rooted in the domain of ethics. A rich tradition of ethics research has produced a typology of ethical frameworks or theories with which individuals make determinations regarding right and wrong. In addition, ethics has been an important point in discussions related to AA (Shaw, 1988). We examine the way in which the two most prominent ethical frameworks may be used as predictors of attitudes toward affirmative action. Additionally we attempt to examine how organizations' support of AA efforts can influence the attitudes of their employees.

Distributive justice norms. The importance of distributive justice in organizations has been supported by several empirical studies. For example, some researchers have shown that it can have a robust effect on a variety of important behaviors in organizations including job performance, and withdrawal behavior such as turnover and absenteeism. In addition, it has been demonstrated that justice is one of the considerations used by individuals to evaluate affirmative action (Heilman, 1994; Heilman \& Herlihy, 1984; Tougas, et al., 1995).

Distributive justice is related to ideas of fairness in the distribution of outcomes. An important facet of the issue of distributive justice is that individuals do not evaluate the fairness of their work outcomes in isolation, but compare their outcomes to those of others in the organization. Thus, one's absolute organizational outcomes may not contain much information in terms of fairness or justice until they are compared to the outcomes obtained by referent others. Indeed, empirical studies demonstrate that considerable variance in individuals' satisfaction with their work outcomes is influenced by these comparisons, over and above the variance explained by the actual magnitude of the outcomes (Sweeney et al., 1990).

Distributive justice includes two separate norms that guide behavior. These norms are identified as the equity norm and the equality norm. Typically the primary justice norm used by individuals to analyze affirmative action is equity (Nacoste, 1990) which reflects an emphasis on one's outcomes relative to one's inputs. In general, the equity norm is used to foster high levels of task performance (Leventhal, 1976). By reinforcing beneficial inputs, the decision maker is expecting individuals to contribute increasing amounts of such inputs to the organization. Equity norms lead to negative attitudes toward affirmative action, in that sex, ethnicity, and other non job-related variables are used as inputs in the equity formula, in affirmative action situations. Both beneficiaries and observers of affirmative action devalue these inputs in their equity comparisons. As a result, they develop feelings of inequity (Nacoste, 1990; Stout \& Buffum, 1993).

An alternative distributive justice norm is equality, in which all participants receive the same outcomes, regardless of their individual performance levels. This norm is used to minimize dissatisfaction and reduce the 
incidence of disruptive, antagonistic behavior on the part of those who might be dissatisfied under an equity allocation rule (Leventhal, 1976).

The conflict between equity and equality norms is discussed in the context of affirmative action by Weining Chang (1996). She argues that although equality is a central concern of the American collective consciousness, public efforts to promote equality have encountered opposition. The nation's need for equality has come into conflict with its equally dominant need for equity or meritocracy, which Chang (1996) describes as "the favored principle for the distribution of wealth and resources (p.94)." In the context of affirmative action, individuals resolve this conflict by evaluating the overall perceived fairness of the policy. This evaluation is influenced by subjective individual differences in the weights assigned to equality and equity. Again, in the specific context of affirmative action, the overall fairness judgment is influenced by the extent to which affirmative action serves to highlight group differences, and individuals' perceptions of the scarcity of organizational resources. Individuals who view organizational resources as fixed in capacity will tend to see affirmative action as a zero-sum game, leading them to oppose the policy.

Veilleux and Tougas (1989) interpret the equity-equality conflict in terms of support for two different kinds of organizational programs. Equity concerns lead to opposition to programs which involve any form of preferential treatment. On the other hand, equality concerns lead to support for equal employment opportunity/diversity initiatives which may in some cases include preferential treatment. As indicated earlier, relatively stable betweenperson differences in the use of equity versus equality norms have been observed. These differences are expected to influence individuals' attitudes toward affirmative action and other identity conscious endeavors. Because numerous studies have studied affirmative action from a equity perspective and not equality perspective, we feel investigating AA when considering equality norms will contribute to the organizational justice literature. As such, the following hypothesis is presented:

H1: Equality norms of distributive justice will relate positively to attitudes toward affirmative action.

\section{Ethics Frameworks}

While justice norms influence individuals' conceptions of fairness, ethics norms influence their notions of broader concepts of right and wrong. For well over a thousand years, philosophers and other scholars have investigated issues of morality and ethics. The substantial body of research on ethics has resulted in a number of competing theories or frameworks which individuals and societies use in making judgments concerning right and wrong. There are no universal standards for judging the inherent rightness or wrongness of most acts. Rather, different individuals will arrive at different ethical conclusions, depending on the analytical perspectives they use. Additionally, individuals are capable of applying varying ethical frameworks to different situations (i.e., there is both within- and between-person variation in predominant ethical framework).

Ethics refers to "inquiry into the nature and grounds of morality where the term morality is taken to mean the moral judgments, standards, and rules of conduct (Taylor, 1975, p.1)." By extension, ethical behavior refers to "that which is shown to be objectively morally correct (permissible, obligatory, or desirable) action and that it is 'ethical' precisely because it is the behavior which is required by the theory (Bommer, et al., 1987, p. 267)." Note that although the terms "ethics" and "morality" are often used interchangeably, there is a technical distinction between the two: Morals and morality refer to conduct itself, whereas ethics refers to the study of this behavior (Tsalikis \& Fritzsche, 1989). Ethics frameworks or theories may be separated into two broad classifications -consequentialist and nonconsequentialist ethical frameworks (De George, 1982; 1990; Hunt \& Vitell, 1986; McDonald \& Pak, 1996).

Consequentialist ethical frameworks. Consequentialism or teleology is an ethical approach that focuses on the outcomes or ends associated with an act or decision. Whether an action is ethical or unethical depends on the final consequences of that action. The teleological framework employed in this study is based on the ideas of selfinterest, utilitarianism, and societal evaluation. In the management context, teleological approaches consider consequences from the perspectives of the interests of a variety of organizational stakeholders (Hunt \& Vitell, 
1986). As introduced earlier, there are both within- and between-person variations in individuals' dominant ethical frameworks.

Wood, et al. (1988) describe this framework as a lower level of moral reasoning which focuses on the furtherance of one's own interest with little regard for higher level, more abstract moral principles. Individuals guided by this framework would only be expected to help others in situations where they derive a net benefit from such help. As such, an act which is considered moral based on a teleological framework may be beneficial to the majority group but extremely harmful to a relatively small number of individuals (Takala \& Uusitalo, 1995). It is possible that the intended beneficiaries of AAPs might be classified as one such "smaller group." As such, individuals who analyze affirmative action from a teleological or consequentialist perspective are likely to focus on the interests of the majority over those of the minority.

We expect that the ethical framework with which one evaluates affirmative action will impact one's attitudes toward it. Specifically:

H2: Consequentialist ethical perspectives will relate negatively to attitudes toward affirmative action.

Nonconsequentialist ethical frameworks. Individuals guided by this framework would only be expected to help others in situations where they derive a net benefit from such help. As such, an act which is considered moral based on a teleological framework may be beneficial to the majority group but extremely harmful to a relatively small number of individuals (Takala \& Uusitalo, 1995). In the more specific organizational context, managers possess a set of generic roles which carry with them a number of duties (Mintzberg, 1973). Based on this perspective, fulfilling the requirements of these roles constitutes ethical behavior (McDonald \& Pak, 1996). As such, we suggest the following:

H3: Non-consequentialist ethical perspectives will relate positively to attitudes toward affirmative action.

\section{Organizational Support As Moderator}

In addition to our investigation of the role of individual differences in impacting attitudes toward affirmative action, this study also examined one significant situational variable. We expect that individuals' attitudinal responses and their ethical judgments of an organizational initiative might be impacted by the workplace environment. Specifically, we assert that employees form their opinions about affirmative action based not only on their personal ethical and justice frameworks but also on whether or not they work in environments in which these programs are supported. We expect organizational support of affirmative action to be a positive moderator.

We propose a form of situational ethics in which judgments of the rightness of affirmative action are tempered by practical constraints. In other words, individuals are more likely to support AA and other related initiatives when it is in their best organizational interest to do so. Although this reasoning supports a direct relationship between organizational support for AA and employee attitudes, our unique contribution resides in hypothesizing an indirect one, where organizational support moderates the relationship between AA attitudes and equality norms, consequentialism, and nonconsequentialism. More formally:

H4: Organizational support of affirmative action will moderate the relationship between equality norms and attitudes toward affirmative action such that when organizational support is high, equality norms will relate more positively to attitudes toward affirmative action.

H5: Organizational support of affirmative action will moderate the relationship between consequentialism and attitudes toward affirmative action such that when employer support is high, consequentialism will relate positively to attitudes toward affirmative action.

H6: Organizational support of affirmative action will moderate the relationship between non-consequentialism and attitudes toward affirmative action such that when employer support is high, consequentialism will relate more positively to attitudes toward affirmative action. 


\section{METHOD}

\section{Sample}

Study participants were upper level undergraduate students from a large Midwestern university. The students were enrolled in a business policy course and participated in the experiment in order to obtain course credit.

Of approximately 600 subjects who began participation in the study, 523 completed the requirements. The sample was approximately 53\% male. Sixty-three percent of respondents identified themselves as White, $4 \%$ Black, 4\% Asian, $1.6 \%$ Asian-American, $0.7 \%$ Hispanic, and $2.8 \%$ of the subjects classified themselves as "Other." The remaining $23.9 \%$ of the sample did not indicate their race/ethnicity.

\section{Measures}

Dependent measure. The dependent measure, attitudes toward affirmative action (targeted at African Americans) was assessed using a modified version of the paper and pencil measure developed by Kravitz (1995). This is a 6-item test with a 5-point, Likert type response scale (1=strongly disagree, $5=$ strongly agree). In previous studies, this scale has demonstrated an internal consistency reliability (Cronbach's alpha) of . 80 - .86 (Kravitz, 1995; Kravitz \& Platania, 1993). In this study, Cronbach's alpha is .83.

Independent measures. Ethical frameworks were collected using the character trait version of the Measure of Ethical Viewpoints (MEV) developed by Brady and Wheeler (1996). This instrument assesses respondents' predispositions toward utilitarianism (consequentialism) and formalism (nonconsequentialism). Respondents rate the importance of various character traits $(1=$ not important to me, $7=$ very important to me). The scale has demonstrated reliability (Brady \& Wheeler, 1996; Schminke et al., 1997) of $.85-.86$ (utilitarianism), and .75 (formalism). The reliability for this study is .93 for consequentialism and .95 for nonconsequentialism.

Our equality measure was developed specifically for this study. It contained items such as "In the organization where I work, I would like it if everyone on the same level received the same pay." Subjects expressed their level of agreement with these items on a 5-point Likert type scale. It demonstrated a reliability of .67.

Employer support for affirmative action was assessed directly using two questions. Subjects simply rated on a five point scale their assessment of how supportive their employer is of affirmative action and how important affirmative action is to the organization. Cronbach's alpha was .72.

Covariates. We used gender as a control variable since research has shown that women hold different attitudes than men about Affirmative Action (Heilman, 1994). Gender was a categorical variable with 0 for women and 1 for men. Perceived job impact and the role of affirmative action in the selection of co-workers were both oneitem scales. As such, internal consistency reliabilities cannot be computed.

\section{RESULTS}

Table 1 provides the means, standard deviations, and correlations for the study variables. Results for the tests of hypotheses are presented in Table 2. Hypothesis 1 posits that equality distributive justice norms relate positively to attitudes toward affirmative action. The results in Table 2, Model 2, indicate that equality norms do not significantly relate to attitudes toward affirmative action (standardized beta $=.032, \mathrm{p}=.46$ ). 
Table 1

Correlations, Means, and Standard Deviations

\begin{tabular}{|c|c|c|c|c|c|c|c|c|c|c|}
\hline No. & Variable & Mean & s.d. & 1 & 2 & 3 & 4 & 5 & 6 & 7 \\
\hline 1 & Sex & 1.22 & .428 & & & & & & & \\
\hline 2 & Perceived job impact & 4.62 & 1.68 & -.022 & & & & & & \\
\hline 3 & Role in selection of co-worker & 3.53 & 1.79 & -.017 & .08 & & & & & \\
\hline 4 & Consequentialism & 5.36 & 1.11 & -.037 & $.105 *$ & -.082 & & & & \\
\hline 5 & Nonconsequentialism & 5.51 & 1.17 & .07 & .075 & $-.105 *$ & $.85^{* *}$ & & & \\
\hline 6 & Equality & 2.77 & .81 & $.19 * *$ & .073 & -.016 & .01 & .016 & & \\
\hline 7 & Organizational support & 3.27 & .91 & $-.18 * *$ & .077 & $-.13 * *$ & .038 & .076 & -.051 & \\
\hline 8 & Attitude toward affirmative action & 3.38 & .88 & .082 & .073 & $-.17 * *$ & $.13 * *$ & $.20 * *$ & .046 & $.24 * *$ \\
\hline
\end{tabular}

Table 2

Results of Regression Analysis of Attitude Toward Affirmative Action ${ }^{\text {a }}$

\begin{tabular}{|c|c|c|c|c|}
\hline Independent Variables & Model 1 & Model 2 & Model 3 & Model 4 \\
\hline Constant & $\begin{array}{l}3.27 * * * \\
(.22)\end{array}$ & $\begin{array}{l}2.63 * * * \\
(.30)\end{array}$ & $\begin{array}{l}1.86^{* * * *} \\
(.32)\end{array}$ & $\begin{array}{l}3.87 * * * \\
(.82)\end{array}$ \\
\hline Sex & $\begin{array}{l}.17 \\
(.14)\end{array}$ & $\begin{array}{l}.10 \\
(.14)\end{array}$ & $\begin{array}{l}.184 \\
(.14)\end{array}$ & $\begin{array}{l}.19 \\
(.14)\end{array}$ \\
\hline Perceived job impact & $\begin{array}{l}.04 \dagger \\
.02)\end{array}$ & $\begin{array}{l}.04 \dagger \\
(.02)\end{array}$ & $\begin{array}{l}.03 \\
.02)\end{array}$ & $\begin{array}{l}.03 \\
(.02)\end{array}$ \\
\hline Role in selection of co-worker & $\begin{array}{l}-.09 * * \\
(.03)\end{array}$ & $\begin{array}{l}-.07 * * \\
(.03)\end{array}$ & $\begin{array}{l}-.06 * * \\
(.02)\end{array}$ & $\begin{array}{l}-.06 * * \\
(.02)\end{array}$ \\
\hline Equality & & $\begin{array}{ll}.03 \\
(.05)\end{array}$ & $\begin{array}{ll}.04 \\
(.05)\end{array}$ & $\begin{array}{l}-.26 \dagger \\
(.15)\end{array}$ \\
\hline Consequentialism & & $\begin{array}{l}-.12 \dagger \\
(.07)\end{array}$ & $\begin{array}{l}.09 \\
(.06) \\
\end{array}$ & $\begin{array}{l}-.58^{*} \\
(.23)\end{array}$ \\
\hline Nonconsequentialism & & $\begin{array}{l}.23 * * * \\
(.06)\end{array}$ & $\begin{array}{l}.20 * * \\
.06)\end{array}$ & $\begin{array}{l}.46^{*} \\
(.21)\end{array}$ \\
\hline Organizational support & & & $\begin{array}{l}.21 * * * \\
(.04)\end{array}$ & $\begin{array}{l}-.43 \dagger \\
(.24)\end{array}$ \\
\hline Organizational support X Equality & & & & $\begin{array}{l}.09 * \\
(.05)\end{array}$ \\
\hline $\begin{array}{l}\text { Organizational support } \mathrm{X} \\
\text { consequentialism }\end{array}$ & & & & $\begin{array}{l}.147 * \\
(.07)\end{array}$ \\
\hline $\begin{array}{l}\text { Organizational support } \mathrm{X} \\
\text { nonconsequentialism }\end{array}$ & & & & $\begin{array}{l}-.07 \\
(.06)\end{array}$ \\
\hline Adjusted $R^{2}$ & .025 & .059 & .100 & .112 \\
\hline $\mathrm{F}$ & $5.52 * * *$ & $6.49 * * *$ & $9.34 * * *$ & $8.32 * * *$ \\
\hline
\end{tabular}

${ }^{a} \mathrm{n}=523$. Standard errors are in parentheses. Two-tailed analysis
$\uparrow \mathrm{p}<.10$
$* \mathrm{p}<.05$
$* * \mathrm{p}<.01$
$* * * \mathrm{p}<.005$

We also offer two hypotheses based on an ethical framework. Hypothesis 2 which posited that consequentialist perspectives relate negatively to attitudes toward affirmative action received no support although it was in the direction we expected (standardized beta $=-.155, \mathrm{p}=.06$ ). Hypothesis 3 which stated that nonconsequentialist perspectives relate positively to affirmative action attitudes received solid support (standardized beta $=.312, \mathrm{p}<.0001)$. As expected, our moderator variable, organizational support for affirmative action, positively relates to attitudes toward affirmative action (standardized beta $=.21, \mathrm{p}<.0001$ ). Thus, it appears that 
employer's stand on AA has an important influence on employee's perception of AA. Hypothesis 4, posits that organizational support of AA will moderate the relationship between equality norms and attitudes toward AA such that when organizational support is high, equality norms will relate positively to attitudes toward AA. Table 2, Model 4, shows that the interaction between employer support and equality norms on attitudes toward AA is positive and significant (standardized beta $=.396, \mathrm{p}=.034$ ) supporting H4. Hypothesis 5, posits that organizational support of AA will moderate the relationship between consequentialism and attitudes toward AA such that when organizational support is high, consequentialism will relate positively to attitudes toward AA. Table 2, Model 4, shows that the interaction between organizational support and consequentialism on attitudes toward AA is significant (standardized beta $=1.05, \mathrm{p}=.029$ ). Therefore, H5 is supported. Hypothesis 6, posits that organizational support of AA will moderate the relationship between nonconsequentialism and attitudes toward AA such that when organizational support is high, nonconsequentialism will relate positively to attitudes toward AA. Table 2, Model 4, shows that the interaction between organizational support and nonconsequentialism on attitudes toward AA is not significant (standardized beta $=-.581, \mathrm{p}=.203$ ). We graph the interactions related to H4 and H5 below.

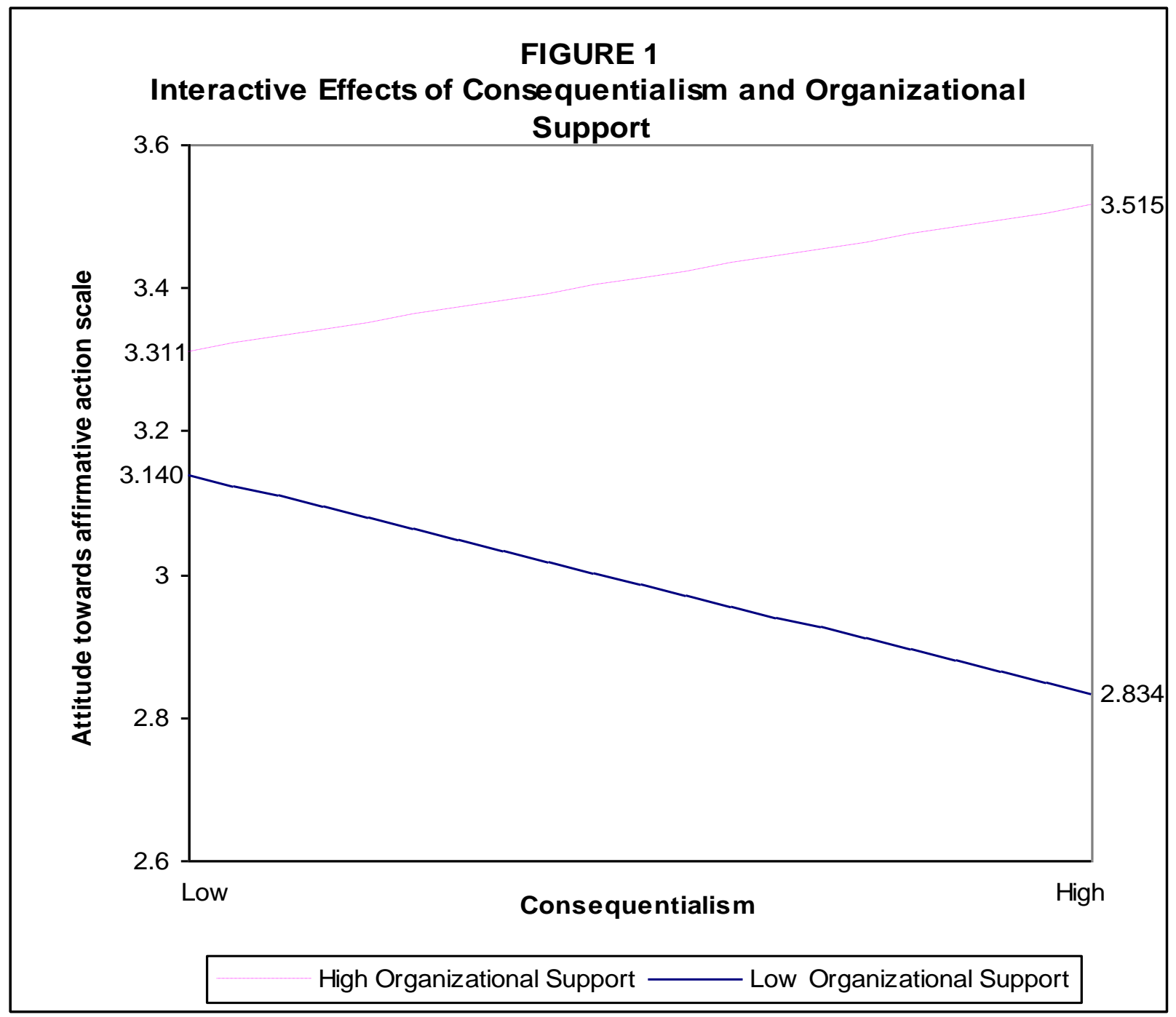




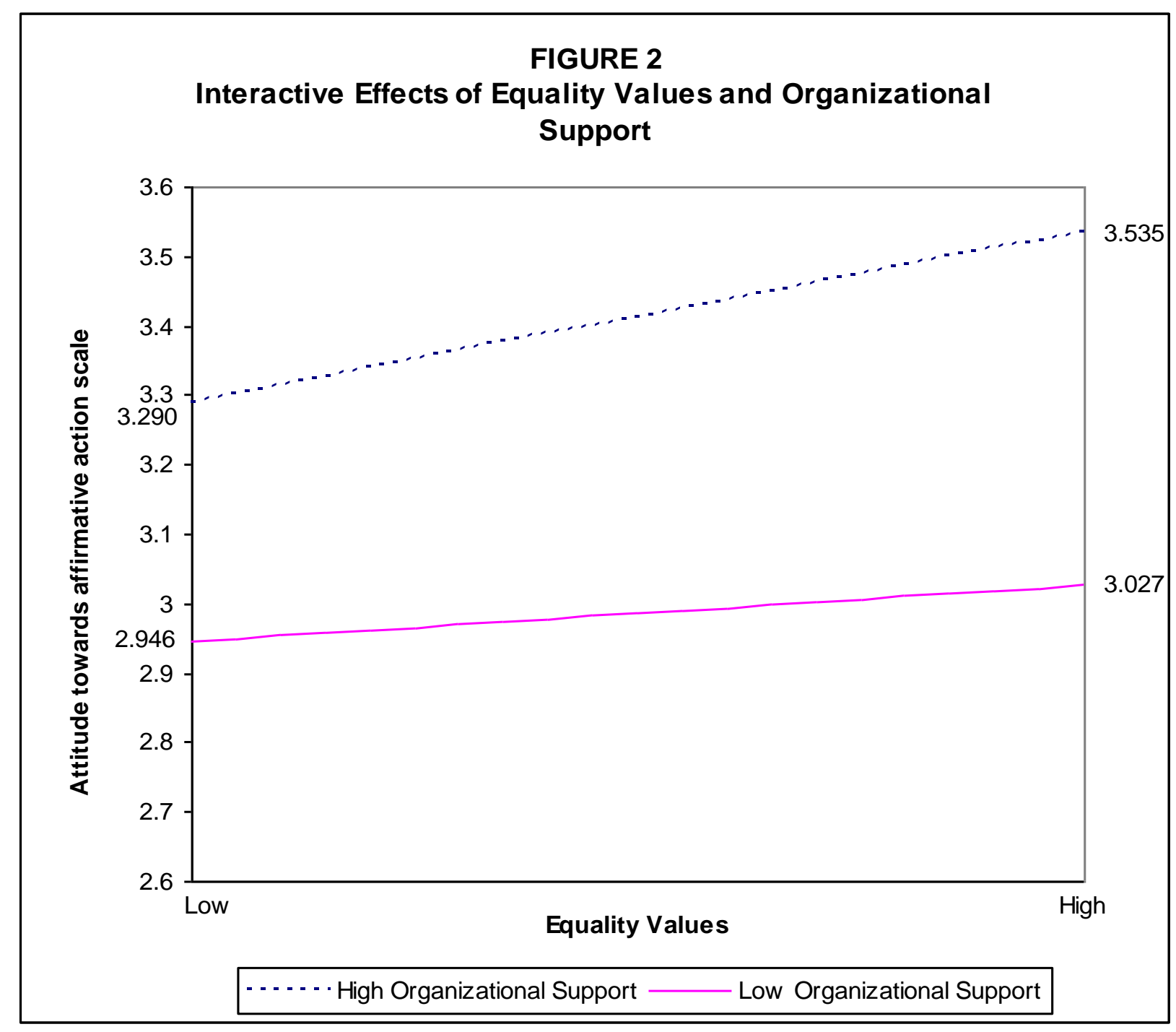

We see that when the organization strongly supports affirmative action, employees with equality norms (Figure 1) as well as consequentialist ethical perspectives (Figure 2) have much more positive attitudes toward affirmative action for African Americans than when such organizational support is low. We discuss the implication of this finding in the next section.

\section{DISCUSSION}

As stated earlier, in spite of pervasive societal opposition to affirmative action and related legislative changes we expect that efforts to promote equal employment opportunity will continue to exist in American organizations for some time to come. Research that adds to the understanding of these efforts holds the potential to alleviate much of the conflict and difficulty surrounding various identity conscious organizational efforts. Although a number of studies have examined the role of various factors in predicting individuals' affective and behavioral responses to affirmative action, this study is unique in attempting to explore how organizational support acts as a powerful contingency factor in how individual values relate to affirmative action attitudes, specifically targeting African Americans. 
Kravitz and Klineberg (2000) suggest that information about AAPs impacts attitudes. This study extends this notion by suggesting that organizational support also has an important effect on AA. The findings of this study clearly suggest that organizations should clarify their positions on affirmative action. Organizational support can include information regarding AAPs. In fact, it may be just as helpful in doing so to clarify what affirmative action is not as well as what it is: Anecdotal evidence suggests that people still think of affirmative action in terms of quotas, preferential treatment and unjustified set-asides (Crosby \& Cordova, 1996; Heilman, McCullough, \& Gilbert, 1996; Kravitz \& Platania, 1993.) When no description of AAPs is provided, respondents' beliefs about AA are determined by individual characteristics (Nacoste, 1994a; Nacoste \& Hummels, 1994). Therefore, it is important for organizations to provide adequate information regarding AAPs and their support for such programs.

Organizational support for AA can be revealed through communication regarding related programs. In fact, Harrison, Kravitz, Mayer, Leslie, and Lev-Arey (2006) suggest that organizational communication about the AAP may be as important as its structure. Ignoring or avoiding discussions regarding AA only serve to increase resistance and negative attitudes. In addition to communication, organizational support can be identified through the use of transparent procedures and justification for AA related decisions.

\section{Limitations And Future Research}

The variables analyzed in this study were collected concurrently. This makes it difficult to rule out spurious causation or to establish causal relationships with certainty. This points to a need for longitudinal designs for future studies. Similarly, future studies should employ experimental designs which not only establish the direction of causality but also demonstrate the practical training effects described in the previous section. Indeed such study demonstrating our ability to adjust attitudes is the next step in our research agenda.

The current study provides valuable additional clarification into the determinants of attitudes toward affirmative action and also points to valuable opportunities both for improving management practice and for further research. The study revealed that more positive attitudes toward affirmative action are associated with equality norms and nonconsequentialist ethical frameworks. In addition, when the employing organization supports affirmative action, equality norms are more positively related to affirmative action attitudes contributing the literature on distributive justice theory. Lastly, consequentialism values become positively related to affirmative action attitudes when the organization supports the policy which contributes to the theoretical frameworks in the ethics literature and suggest the need to consider context more succinctly. It also provides interesting preliminary findings indicating unique attitudinal reactions to programs targeting African Americans.

Dr. Edward Fubara serves as Assistant Professor and Director of the MBA Program in the Lundy-Fetterman School of Business at Campbell University. He holds MBA and Ph.D. degrees in Management from Michigan State University's Eli Broad Graduate School of Management. His work has been published in the Journal of Applied Social Psychology and the Journal of Management Studies. His research interests are in management of diversity, ethics, management of Christian organizations and management applications for developing nations.

Dr. Amy McMillan-Capehart serves as Assistant Professor of Management at East Carolina University. She received her D.B.A. from Louisiana Tech University. Her work has been published in Group and Organization Management, Journal of Business and Management, and Journal of Business Research. Her research interests include organizational diversity, organizational culture, and person-organization fit.

Dr. Orlando C. Richard serves as an Associate Professor of Management at the University of Texas at Dallas. He received her Ph.D. from the University of Kentucky. His research has been published in the Academy of Management Journal, Journal of Business Research, and Strategic Management Journal. His research interests include workforce diversity and firm performance, mentoring relationships, and organizational justice. 


\section{REFERENCES}

1. Akaah, I.P. (1997). Influence of deontological and teleological factors on research ethics evaluations. Journal of Business Research 39, 71-81.

2. Bertrand, M., \& Mullainathan, S. (2004). Are Emily and Greg more employable than Lakisha and Jamal? A field experiment on labor market discrimination. American Economic Review 94, 991-1013.

3. Blackstone, W.T., \& Heslep, R.D. (1977). Social justice and preferential treatment: Women and racial minorities in education and business. University of Georgia Press.

4. Bobo, L., \& Kluegel, J.R. (1993). Opposition to race-targeting: Self-interest, stratification, ideology, or racial attitudes? American Sociological Review 58, 443-464.

5. Bommer, M., Gratto, C., Gravander, J., \& Tuttle, M. (1987). A behavioral model of ethical and unethical decision making. Journal of Business Ethics 6, 265-280.

6. Brady, F.N., \& Wheeler, G.E. (1996). An empirical study of ethical predispositions. Journal of Business Ethics 15, 927-940.

7. Chang, W.C. (1996). Toward equal opportunities: Fairness, values, and affirmative action programs in the U.S. Journal of Social Issues 52, 93-97.

8. Clayton, S.D., \& Crosby, F.J. (1992). Justice, gender, and affirmative action. Ann Arbor, MI: University of Michigan Press.

9. Cropanzano, R., Slaughter, J.E., \& Bachiochi, P. (2005). Organizational justice and black applicants' reactions of affirmative action. Journal of Applied Psychology 92, 1168-1184.

10. Crosby, F.J., \& Cordova, D.I. (1996). Words worth of wisdom: Toward an understanding of affirmative action. Journal of Social Issues 52, 33-49.

11. Crosby, F.J., Iyer, A., \& Sincharoen, S. (2006). Understanding affirmative action. Annual Review of Psychology 57, 585-611.

12. De George, R.T. (1982). Business ethics New York: Macmillan.

13. De George, R.T. (1990). Business ethics. New York: Macmillan.

14. Fried, Y., Levi, A., Billings, S., \& Browne, K. (2001). The relationship between political ideology and attitudes toward affirmative action among African Americans: The moderating effect of racial discrimination in the workplace. Human Relations 54, 561-584.

15. Harrison, D.A., Kravitz, D., Mayer, D., Leslie, L., \& Lev-Arey, D. (2006). Understanding attitudes toward affirmative action programs in employment: Summary and meta-analysis of 35 years of research. Journal of Applied Psychology 91, 1013-1036.

16. Heilman, M.E. (1994). Affirmative action: Some unintended consequences for working women. Research in Organizational Behavior 16, 125-169.

17. Heilman, M.E., \& Herlihy, J.M. (1984). Affirmative action, negative reaction? Some moderating conditions. Organizational Behavior and Human Performance 33, 204-213.

18. Heilman, M.E., McCullough, W.F., \& Gilbert, D. (1996). The other side of affirmative action: reactions of nonbeneficiaries to sex-based preferential selection. Journal of Applied Psychology 81, 346-357.

19. Hitt, M.A., \& Keats, B.W. (1984). Empirical identification of the criteria for effective affirmative action programs. The Journal of Applied Behavioral Science 20, 203-223.

20. Hunt, S.D., \& Vitell, S. (1986). A general theory of marketing ethics. Journal of Macromarketing 6 (1), pp. 5-16.

21. Johnston, W.B., \& Packer, A.E. (1987). Workforce 2000: Work and workers for the 21 st century. Indianapolis, IN: Hudson Institute.

22. Kluegel, J.R., \& Smith, E. R. (1983). Affirmative action attitudes: Effects of self-interest, racial affect, and stratification beliefs on whites' views. Social Forces 61, 797-824.

23. Kluegel, J.R., \& Smith, E.R. (1986). Beliefs about inequality: Americans' views of what is and what ought to be. New York: Aldine de Gruyter.

24. Konrad, A.M. \& Linnehan, F. (1995). Race and sex differences in line managers' reactions to equal employment opportunity and affirmative action interventions. Group and Organizational Management 20, 409-440.

25. Kravitz, D.A. (1995). Attitudes toward affirmative action plans directed at blacks: Effects of plan and individual differences. Journal of Applied Social Psychology 25, 2192-2220. 
26. Kravitz, D.A. \& Klineberg, S.L. (2000). Reactions to two versions of affirmative action among Whites, Blacks, and Hispanics. Journal of Applied Psychology 85, 597-611.

27. Kravitz, D.A. \& Platania, J. (1993). Attitudes and beliefs about affirmative action: Effects of target and of respondent sex and ethnicity. Journal of Applied Psychology 78, 928-938.

28. Leventhal, G.S. (1976). The distribution of rewards and resources in groups and organizations. In L. Berkowitz \& E. Walster (Eds.), Advances in experimental social psychology, vol. 9, (pp. 91-131). New York: Academic Press.

29. McDonald, G., \& Pak, P.C. (1996). It's all fair in love and war: Cognitive philosophies in ethical decision making. Journal of Business Ethics 15, 973-996.

30. Mintzberg, H. (1973). The nature of managerial work. New York: Harper \& Row.

31. Nacoste, R.W. (1990). Sources of stigma: Analyzing the psychology of affirmative action. Law \& Policy 12, 175-195.

32. Nacoste, R.W. (1994). Policy schemas for affirmative action. In L.Heath, R.S. Tinsdale, J.Edwards, E.J. Posavac, F.B. Bryant, E.Henderson-King, et al. (Eds.) Applications of heuristics and biases to social issues, (pp. 205-221). New York: Plenum.

33. Nacoste, R.W. \& Hummels, B. (1994). Affirmative action and the behavior of decision makers. Journal of Applied Social Psychology 24, 595-613.

34. Opotow, S. (1996). Affirmative action, fairness, and the scope of justice. Journal of Social Issues 52 (4), 19-24.

35. Schminke, M., Ambrose, M.L., \& Noel, T.W. (1997). The effect of ethical frameworks on perceptions of organizational justice. Academy of Management Journal 40, 1190-1207.

36. Shaw, B. (1988). Affirmative action: An ethical evaluation. Journal of Business Ethics 7, 763-770.

37. Stout, K.D. \& Buffum, W.E. (1993). The commitment of social workers to affirmative action. Journal of Sociology \& Social Welfare 20 (22), 123-135.

38. Sweeney, P.D., McFarlin, D.B., \& Inderrieden, E.J. (1990). Using relative deprivation theory to explain satisfaction with income and pay level: A multistudy examination", Academy of Management Journal 33, 423-436.

39. Takala, T., \& Uusitalo, O. (1995). Retailers' professional ethical dilemmas: the case of Finnish retailing business. Journal of Business Ethics 14, 893-907.

40. Taylor, P.W. (1975). Principles of ethics: An introduction. Encino, CA: Dickinson Publishing Company.

41. Taylor-Carter, M., Doverspike, D., \& Alexander, R. (1995). Message effects on the perception of fairness of gender-based affirmative action: A cognitive response theory-based analysis. Social Justice Research, 8 , 285-303.

42. Tougas, F., Crosby, F., Joly, S., \& Pelchat, D. (1995). Men's attitudes toward affirmative action: Justice and intergroup relations at the crossroads. Social Justice Research 8 (1), 57-71.

43. Tsalikis, J., \& Fritzsche, D.J. (1989). Business ethics: A literature review with a focus on marketing ethics", Journal of Business Ethics 8, 695-743.

44. Veilleux, F. \& Tougas, F. (1989). Male acceptance of affirmative action programs for women: The results of altruistic or egoistical motives? International Journal of Psychology 24, 485-496.

45. Wood, J.A., Longnecker, J.G., McKinney, J.A., \& Moore, C.W. (1988). Ethical attitudes of students and business professionals. Journal of Business Ethics 7, 249-258. 